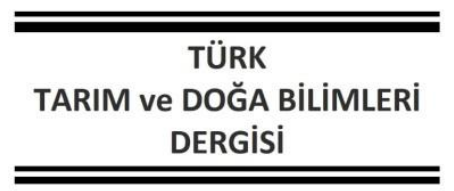

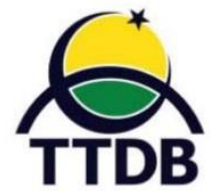

www.dergipark.gov.tr/turkjans

Araştırma Makalesi

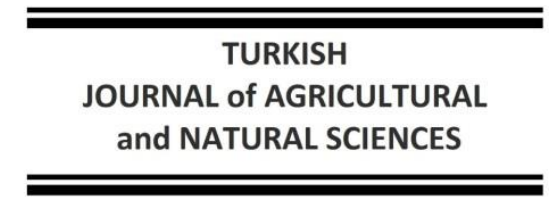

and NATURAL SCIENCES

\title{
Bazı Meyve Bahçelerinin Beslenme Durumlarının Belirlenmesi
}

\author{
Ahu Alev ABACI BAYAR ${ }^{1 *}$, Selma BOYACl ${ }^{2}$ \\ ${ }^{1}$ Kırşehir Ahi Evran Üniversitesi, Ziraat Fakültesi, Peyzaj Mimarlığı Bölümü, Kırşehir \\ ${ }^{2}$ Kırşehir Ahi Evran Üniversitesi, Ziraat Fakültesi, Bahçe Bitkileri Bölümü, Kırşehir \\ *Sorumlu Yazar: ahu.abaci@ahievran.edu.tr
}

Geliş Tarihi: 17.03.2021 Düzeltme Geliş Tarihi: 01.10.2021 Kabul Tarihi: 13.10.2021

\section{Öz}

Bu çalışma ile Kırşehir ilinde yetiştiriciliği yapılan armut, şeftali, kiraz, üzüm, ceviz ve elma meyve türlerinde yaprak ve toprak analizleri ile toprağın verimlilik durumu ve bitkilerin besin elementi düzeylerinin belirlenmesi amaçlanmıştır. Toprakların kumlu tınlı bünyede olduğu ve tuzluluk sorununun olmadığı $\mathrm{pH}^{\prime}$ sının 8.07 ile 8.44 arasında değişim gösterdiği, \% 93.3'ünde organik madde miktarı düşük ve \% 80'inde kireci fazla bulunmuştur. Topraktaki azot (N); \% 0.04-0.18, fosfor (P); 2.52-48.43 $\mathrm{mg} \mathrm{kg}^{-1}$, potasyum (K); 75.32-809.36 mg $\mathrm{kg}^{-1}$, kalsiyum (Ca); 3674.47-13478.67 mg kg-1, magnezyum (Mg); 96.25-1801.00 mg kg-1, demir (Fe); 1.97-11.28 $\mathrm{mg} \mathrm{kg}{ }^{-1}$, bakır (Cu); 0.10-7.95 mg kg-1 , çinko (Zn); 0.009-2.78 $\mathrm{mg} \mathrm{kg}^{-1}$, mangan (Mn); 2.82-24.32 mg kg ${ }^{-1}$ değerleri arasında değişim göstermiştir. Topraklar N, P, Zn ve Mn bakımından fakir (sırasıyla \% 46.7, \% 60, \% 60, \% 76.7), $\mathrm{K}, \mathrm{Mg}$ ve Fe bakımından yüksektir (sırasıyla \% 90, \% 56.6, \% 50). Yaprak örneklerinin \% 33.3'ünde N, \%20'sinde $P$, \% 46.7'sinde $K$, \% 53.3'ünde Ca, \% 46.7'sinde Zn, \%100'ünde Cu noksanlığı belirlenmiş ve \% 86.7'sinde Fe ve $\mathrm{Mn}$ elementi yeterlilik sınııında saptanmıştır. Armut yapraklarında; $\mathrm{N}, \mathrm{K}, \mathrm{Cu}$, şeftalide; $\mathrm{Cu}$, Fe, kirazda; $\mathrm{Ca}, \mathrm{Cu}, \mathrm{K}$, $\mathrm{Zn}$, üzümde; $\mathrm{P}, \mathrm{K}, \mathrm{Cu}, \mathrm{N}$, cevizde; $\mathrm{K}, \mathrm{Cu}$, elmada; $\mathrm{Ca}, \mathrm{Cu}$ noksanlıkları belirlenmiş, $\mathrm{Mg}$ ve $\mathrm{Mn}$ açısından sorun saptanmamıştır. Toprak ve yaprak örneklerinin analizlerinde önemli düzeyde pozitif ve negatif korelasyonlar tespit edilmiştir.

Anahtar kelimeler: Beslenme durumu, meyve bahçesi, toprak, yaprak

\section{Determination of Nutritional Status of Some Orchards}

\begin{abstract}
In this study, it was aimed to determine the fertility status of the soil and the nutrient levels of the plants by leaf and soil analysis of pear, peach, cherry, grape, walnut and apple fruit species cultivated in Kırşehir. It has been found that the soils are of sandy-loam structure and there is no salinity problem, the $\mathrm{pH}$ varies between 8.07 and 8.44 , the amount of organic matter is low in $93.3 \%$ and lime is high in $80 \%$. The soils of $\mathrm{N}$ content; $0.04-0.18 \%, \mathrm{P} ; 2.52-48.43 \mathrm{mg} \mathrm{kg}{ }^{-1}, \mathrm{~K}$; $75.32-809.36 \mathrm{mg} \mathrm{kg}$, Ca; $3674.47-13478.67 \mathrm{mg} \mathrm{kg}^{-1}, \mathrm{Mg}^{-}$ 96.25-1801.00 mg kg-1, Fe; 1.97-11.28 mg kg-1, Cu; 0.10-7.95 mg kg-1, Zn; 0.009-2.78 mg kg-1, Mn; 2.82-24.32 mg $\mathrm{kg}^{-1}$ of it varied between. The soils are poor in N, P, Zn and $\mathrm{Mn}$ (respectively $46.7 \%, 60 \%, 60 \%, 76.7 \%$ ), they are high in $\mathrm{K}, \mathrm{Mg}$ and Fe (respectively $90 \%, 56.6 \%, 50 \%$ ). The leaf samples were determined the deficiency of $\mathrm{N}$ in $33.3 \%$ of, $\mathrm{P}$ in $20 \%, \mathrm{~K}$ in $46.7 \%, \mathrm{Ca}$ in $53.3 \%, \mathrm{Zn}$ in $46.7 \%, \mathrm{Cu}$ in $100 \%$ were determined and $86.7 \% \mathrm{Fe}$ and $\mathrm{Mn}$ were at the limit of adequacy. In pear leaves in; $\mathrm{N}, \mathrm{K}, \mathrm{Cu}$, peach; $\mathrm{Cu}$, Fe, cherry; $\mathrm{Ca}, \mathrm{Cu}, \mathrm{K}, \mathrm{Zn}$, grapes; $\mathrm{P}$, $\mathrm{K}, \mathrm{Cu}, \mathrm{N}$, walnut; $\mathrm{K}, \mathrm{Cu}$, apple; $\mathrm{Ca}$, $\mathrm{Cu}$ deficiencies were determined, and no problem was found in terms of $\mathrm{Mg}$ and $\mathrm{Mn}$. Significant positive and negative correlations were found in the analysis of soil and leaf samples.
\end{abstract}

Key words: Nutritional status, orchard, soil, leaf 


\section{Giriş}

Ülkemizde meyve yetiştiriciliği önemli bir yere sahip olup, tarım alanlarının \% 5.5 oranındaki kısmında meyvecilik yapılmaktadır. Başarılı bir meyve yetiştiriciliği için; iklim, toprak, sulama, bitki koruma ve bitki besleme gibi faktörlerden bazıları yetiştiriciler tarafından kontrol edilebilirken, bazıları kontrol edilememektedir. Bitki besleme, meyveciliğin gerekli uygulamalarından biridir ve kontrol edilen faktörler arasında yer almaktadır (Herrera, 2001).

Genel olarak tüm meyve bahçelerine önerilebilecek bir bitki besleme yöntemi bulunmamaktadır. Sürgünlerin iyi uzaması, ağaç büyümesinin orta kuvvette olması ve yüksek oranda pazarlanabilir kaliteli meyve elde edilmesi için belirlenen besleme yöntemi mutlaka budama, meyve seyreltilmesi, bitki koruma önlemleri gibi kültürel uygulamalarla karşılıklı olarak ilişkilendirilmelidir. Meyve ağaçlarının büyüme ve verim açısından verdikleri tepkiler, üzerinde yetiştikleri toprak tipine doğrudan bağlıdır (Childers ve ark., 1995). Bitkide ve toprakta besin elementi varlığının belirlenmesinde yaprak ve toprak analizleri kullanılmaktadır. Bu nedenle dünyada ve ülkemizde birçok araştırıcı meyve yetiştiriciliği yapılan alanlarda, verim ve kalitenin artırılması amacıyla, toprak ve yaprak analizleri ile bitki beslemeye yönelik çok sayıda çalışma yapmışlardır (Zhang ve ark., 1995; Pınar ve ark., 2008; Uçgun ve ark., 2013). Kırşehir ilinde 40.312 dekarlık alanda, 12.810 ton meyve üretimi yapılmaktadır (Anonim, 2020a). İlde meyvecilik faaliyeti olarak üzüm, elma, ceviz, armut, kayısı, kiraz, badem, erik, vişne gibi meyve türlerinin yetiştiriciliğinin yapılmasının yanı sıra; ceviz, üzüm ve elma yetiştiriciliği önemli bir yere sahiptir (Boyacı ve ark., 2017). Bu çalışma Kırşehir ilinde meyve bahçelerinin toprak verimliliğini ortaya çıkarmak ve bitkilerde besin elementi düzeylerini belirlemek amacıyla, yaprak ve toprak örnekleri analiz edilerek, elde edilen sonuçlar yeterlilik düzeyleri ile karşılaştırılmıştır.

\section{Materyal ve Metot}

Çalışmanın yürütüldüğü Kırşehir, İç Anadolu Bölgesi'nin Orta Kızılırmak bölümünde yer alan, kışları soğuk ve yağışlı, yazları sıcak ve kurak olan karasal iklim hakimdir. Uzun yıllar ortalamasına göre, bölgede en yüksek yağış Aralık, en düşük yağış ise Ağustos ayında düşmektedir. Yıllık ortalama sıcaklık $11.5^{\circ} \mathrm{C}$ olup en soğuk ay Ocak, en sıcak ay ise Temmuz'dur (Anonim 2020b).

Toprak Analizleri: Kırşehir il Tarım ve Orman Müdürlüğü Çiftçi Kayıt Sistemi'ne göre, merkez ilçede meyve bahçelerinin (armut, şeftali, kiraz, üzüm, ceviz, elma) dağılımına göre 15 meyve bahçesi belirlenmiştir. Meyve bahçeleri tesis sonrası olduğu için bozulmuş toprak örnekleri ağaç taç izdüşümünden bahçeyi temsil edecek sayıda 030 ve $30-60 \mathrm{~cm}$ derinlikteki toprak katmanından örnekler alınmıştır. Toprakların bünye sınıfı; Gee ve Bauder (1986) tarafından bildirilen bouyoucus hidrometre yöntemiyle, toprak $\mathrm{pH}^{\prime} \mathrm{s}$ । ve elektriksel iletkenlik değeri sature haldeki örneklerde cam elektrotlu pH ve EC metre ile (Bayraklı, 1987), toplam kireç; Scheibler kalsimetresi ile (Nelson, 1982), organik madde; Modifiye Walkley-Black yöntemine (Nelson ve Sommers, 1996) ve toplam $\mathrm{N}$ içeriği Kjeldahl metoduna göre belirlenmiştir (Bremner ve Mulvaney, 1982). Bitkiye yarayışlı Ca, $\mathrm{Mg}$ ve $\mathrm{K} ; 1 \mathrm{~N}$ amonyum asetat $\left(\mathrm{NH}_{4} \mathrm{OAC}, \mathrm{pH}=7\right)$ yöntemine göre (Helmke ve Sparks, 1996), bitkiye yarayışı $\mathrm{P}$; $0.5 \mathrm{M} \mathrm{NaHCO}_{3}$ yöntemiyle (Kuo, 1996), ekstrakte edilebilir $\mathrm{Fe}, \mathrm{Cu}, \mathrm{Zn}$ ve $\mathrm{Mn}$; DTPA yöntemiyle (Lindsay ve Norvell, 1978) belirlenmiştir. Element konsatrasyonları; Flame Fotometre, UV-VIS ve AAS (Agilent 240 AAS) ile ölçülmüştür.

Bitki analizleri: Analiz için yaprak örnekleri Jones ve Case (1990) tarafından açıklandığı gibi hazırlanmıştır. Bitki örnekleri, $\mathrm{HNO}_{3}$ ve $\mathrm{HClO}_{4}$ kullanılarak yapılan blok-parçalama yöntemine göre (Jones ve Case, 1990) yakılmış ve süzükler elde edilmiştir. AAS ve Flame fotometrede elementel ( $\mathrm{K}, \mathrm{Ca}, \mathrm{Mg}, \mathrm{Na}, \mathrm{Mn}, \mathrm{Cu}, \mathrm{Zn}, \mathrm{Fe}$ ) okumalar gerçekleştirilmiştir. Bitkilerde toplam N; Bremner ve Mulvaney (1982) tarafından bildirilen Kjeldahl metoduna göre belirlenmiştir.

İstatistiksel analizler: Çalışma alanı toprakları ve bitki örneklerindeki bazı kimyasal ve fiziksel analizlerden elde edilen sayısal veriler, SPSS programı (IBM SPSS Advanced Statistics version 19.0.0) kullanılarak Pearson korelasyon analizi ile değerlendirilmiştir (Açıkgöz ve ark., 1994).

\section{Bulgular ve Tartışma}

Toprak örneklerine ait bulgular Çizelge 1'de verilmiştir. Toprağın bünyesi kumlu tındır (Kacar, 2009). Meyve bahçesi topraklarının elektriki iletkenliği 0.14-0.50 dS $\mathrm{m}^{-1}$ arasındadır. Maas (1986)'a göre tuzsuz sınıfında yer almaktadır. Toprak pH değeri 8.07-8.44 arasında değişim göstermiştir. Richards (1954)'a göre orta derece alkalin sınıfındadır. Toprak $\mathrm{pH}^{\prime} \mathrm{sı}$ besin elementlerinin yıkanması ve elverişliliği, elementlerin toksisitesi gibi bitkinin gelişimi için gerekli olan en önemli kimyasal toprak özelliklerinden biridir. Zengin ve ark. (2007) meyve yetiştiriciliği için en uygun $\mathrm{pH}$ aralığının 6.5-7.5 olduğunu bildirmişlerdir. Buna göre bahçe topraklarının ortalama $\mathrm{pH}^{\prime} \mathrm{sı} 8.27$ olması meyve 
yetiştiriciliği için uygun bulunan $\mathrm{pH}$ değerlerinden

(6.5-7.5) daha yüksek bulunmuştur.

Çizelge 1. Meyve türlerine göre, alan topraklarının bazı fiziksel ve kimyasal analiz sonuçları ve betimleyici istatistikler.

\begin{tabular}{|c|c|c|c|c|c|c|c|c|}
\hline Özellik & Birim & Ortalama & Varyans & SD & Çarpıklık & Basıklık & Max. & Min. \\
\hline Kil & $\%$ & 11.42 & 34.014 & 5.832 & 0.163 & -0.779 & 24.67 & 3.03 \\
\hline Silt & $\%$ & 12.24 & 28.744 & 5.361 & 0.225 & -0.517 & 24.62 & 2.82 \\
\hline Kum & $\%$ & 76.333 & 113.934 & 10.674 & -0.172 & -0.920 & 91.53 & 54.74 \\
\hline $\mathrm{pH}$ & & 8.27 & 0.008 & 0.089 & -0.196 & -0.252 & 8.44 & 8.07 \\
\hline EC & $\mathrm{dS} \mathrm{m}^{-1}$ & 0.27 & 0.007 & 0.084 & 1.25 & 1.65 & 0.50 & 0.14 \\
\hline $\mathrm{CaCO}_{3}$ & $\mathrm{~g} \mathrm{~kg}^{-1}$ & 177.24 & 4688.038 & 68.469 & 0.406 & -0.713 & 307.83 & 76.75 \\
\hline OM & $\mathrm{g} \mathrm{kg}^{-1}$ & 14.137 & 43.876 & 6.624 & 1.520 & 2.630 & 34.14 & 5.32 \\
\hline$P$ & $\mathrm{mg} \mathrm{kg}^{-1}$ & 11.286 & 127.005 & 11.270 & 2.030 & 3.714 & 48.43 & 2.52 \\
\hline K & $\mathrm{mg} \mathrm{kg}^{-1}$ & 437.417 & 30633.713 & 175.025 & -0.200 & 0.104 & 809.36 & 75.32 \\
\hline $\mathrm{Ca}$ & $\mathrm{mg} \mathrm{kg}^{-1}$ & 6039.148 & 3109383.70 & 1763.344 & 2.595 & 10.527 & 13478.67 & 3674.47 \\
\hline $\mathrm{Mg}$ & $\mathrm{mg} \mathrm{kg}^{-1}$ & 619.975 & 155157.902 & 393.901 & 1.132 & 1.263 & 1801.00 & 96.25 \\
\hline$N$ & $\%$ & 0.096 & 0.001 & 0.035 & 0.455 & -0.052 & 0.18 & 0.04 \\
\hline $\mathrm{Fe}$ & $\mathrm{mg} \mathrm{kg}^{-1}$ & 5.158 & 6.783 & 2.604 & 0.765 & -0.331 & 11.28 & 1.97 \\
\hline $\mathrm{Cu}$ & $\mathrm{mg} \mathrm{kg}^{-1}$ & 1.931 & 4.021 & 2.005 & 1.264 & 1.346 & 7.95 & 0.10 \\
\hline $\mathrm{Zn}$ & $\mathrm{mg} \mathrm{kg}^{-1}$ & 0.861 & 0.428 & 0.654 & 1.129 & 1.931 & 2.78 & 0.09 \\
\hline $\mathrm{Mn}$ & $\mathrm{mg} \mathrm{kg}^{-1}$ & 9.383 & 23.173 & 4.814 & 1.160 & 1.839 & 24.32 & 2.82 \\
\hline
\end{tabular}

$\mathrm{P}=$ Yarayışlı fosfor, $\mathrm{K}=\mathrm{Alınabilir}$ potasyum, $\mathrm{Ca}=\mathrm{Alınabilir}$ kalsiyum, Mg=Alınabilir magnezyum, Fe=Alınabilir demir, $\mathrm{Cu}=$ Alınabilir bakır, $\mathrm{Mn}=A$ lınabilir mangan, $\mathrm{Zn}=$ Alınabilir çinko, $\mathrm{N}=$ Toplam azot, $\mathrm{SD}=\mathrm{Standart}$ sapma

Bundan dolayı toprakların tamamı pH açısından meyve ağaçlarının beslenmesinde problem oluşturabilecek düzeydedir.

Toprak verimliliği açısından büyük öneme sahip organik madde (OM) içeriği en düşük $5.32 \mathrm{~g}$ $\mathrm{kg}^{-1}$, en yüksek $34.14 \mathrm{~g} \mathrm{~kg}^{-1}$ ve ortalama $14.137 \mathrm{~g}$ $\mathrm{kg}^{-1}$ 'dır. Ülgen ve Yurtsever (1974)'e göre OM, toprakların \% 6.7'sinde orta, \% 23.3'ünde çok az, \% 70'inde az düzeydedir. Organik maddenin topraklardaki yetersizliği makro ve mikro besin elementi eksiklikleri yanında toprakların birçok özelliğini de olumsuz yönde etkileyecektir. Bitki besin elementlerinin alınabilirliğini ve yarayışlıı̆̆ını direkt yada dolaylı olarak etkilemekte, bakır elementi ile organik madde arasında kompleksler oluştuğundan yarayışlılığı azalmakta ve alınamaz formdaki mikro besin elementlerinin yarayışlılığını arttırmaktadır (Yağmur ve Okur, 2015). Bunun yanı sıra, OM, bitki besin maddesi kaynağı olduğu gibi toprağın birçok fiziksel ve kimyasal özelliklerini iyileştirmektedir. Bundan dolayı meyve yetiştiriciliğinde, organik madde içeriği düşük olan topraklarda organik gübre kullanılmalıdır.

Toprakların kireç içeriği en düşük 76.75 g kg1, en yüksek $307.83 \mathrm{~g} \mathrm{~kg}^{-1}$, ortalama $177.24 \mathrm{~g} \mathrm{~kg}$ ${ }^{1}$ 'dır. Ülgen ve Yurtsever (1974)'e göre topraklar orta kireçli ve çok fazla kireçli sınıfındadır. Kireç oranının $\mathrm{pH}$ değeriyle doğru orantılı olduğu ve $\mathrm{CaCO}_{3}$ içeren topraklarda $\mathrm{pH}^{\prime}$ nın arttığı ve 7.8-8.2 arasında değiştiği bildirilmiştir (Heckman, 2004). Toprak pH'sının yüksek ve yaklaşık \% 80'inde kireç içeriğinin fazla olması topraktaki özellikle $P$ ve mikro (Fe, Zn, Cu, Mn) elementlerin bitkiler tarafından alımı ve yarayışıılığı açısından potansiyel tehlike oluşturmakta (Kacar ve Kaykat, 1998) ve kireç topraktaki birçok besin elementini yarayışsız hale getirmektedir. Özellikle kireçli ve pH'sı yüksek topraklarda bitkilerin fosfordan yararlanması azalırken, toprak çözeltisinde yüksek miktarda bulunan $\mathrm{K}$ ve $\mathrm{Ca}$ gibi elementler $\mathrm{Mg}$ alınımını azaltarak noksanlığa neden olabilmektedir. Kireçli ana materyal üzerinde oluşmuş kurak bölge topraklarında, Ca diğer bazı besin elementlerinin, 
özellikle mikro elementlerin alınmasında antagonistik etki oluşturacak kadar fazla bulunabilmektedir (Yıldız ve Uygur, 2016). Bilindiği gibi, kireç topraktaki birçok besin elementini yarayışsız hale getirmekte ve bunun için sonbaharda toprağa kükürt ilavesi önerilmektedir (Zengin ve ark., 2007). Çalışma topraklarında orta derecede alkalin ve yüksek kireç içeriği, mikro elementlerin kullanımını olumsuz etkilemekte, bu yüzden toprakta mikro besin elementi yönünden problem yaşanabilmektedir.

Meyve bahçeleri topraklarının yarayışlı $P$ miktarı en düşük $2.52 \mathrm{mg} \mathrm{kg}^{-1}$, en yüksek $48.43 \mathrm{mg}$ $\mathrm{kg}^{-1}$, ortalama $11.286 \mathrm{mg} \mathrm{kg}{ }^{-1}$ dır. Sillanpää (1990)'ya göre sırasıyla az, fazla ve yeterli sınıfında bulunmuştur. Toprakların \% 26.7'sinde yarayışlı P yeterli iken \% 60'ında çok az ve az seviyesindedir. Çoğu meyve ağaçlarında, ağaçların optimum gelişebilmesi, meyve kalitesinin istenilen özelliklerde olması için mutlak gerekli bir bitki besin elementi de potasyumdur (Yağmur ve Okur, 2015). Alan topraklarının yarayışlı $\mathrm{K}$ miktarı en düşük $75.32 \mathrm{mg} \mathrm{kg}^{-1}$, en yüksek $809.36 \mathrm{mg} \mathrm{kg}^{-1}$ ve ortalama $437.417 \mathrm{mg} \mathrm{kg}^{-1}$ dir. Sumner ve Miller (1996)'e göre toprakların K içeriği az ve fazla arasında değişim göstermiştir. Toprakların \% 90'ında K seviyesi yeterlilik sınırının (140-370 mg $\mathrm{kg}^{-1}$ ) üzerindedir. Topraklarda yarayışı $\mathrm{Ca}$ miktarı en düşük $3674.47 \mathrm{mg} \mathrm{kg}^{-1}$, en yüksek $13478.67 \mathrm{mg}$ $\mathrm{kg}^{-1}$ ve ortalama $6039.148 \mathrm{mg} \mathrm{kg}^{-1}$ dir. Sumner ve Miller (1996)'e göre fazla ve çok fazla sınıfındadır. Kurak bölge topraklarında Ca elementinin fazlalığı topraktaki K, P, Fe elementlerinin bitkilerin yararlanamayacağı formlara dönüşerek antagonistik etki yapmasına neden olmaktadır (Aktaş ve Ateş, 1998; Boşgelmez ve ark., 2001). Bahçe topraklarında yarayışlı Mg miktarı en düşük $96.25 \mathrm{mg} \mathrm{kg}^{-1}$ ile az, en yüksek $1801.00 \mathrm{mg} \mathrm{kg}^{-1}$ ile fazla ve ortalama $619.975 \mathrm{mg} \mathrm{kg}^{-1}$ dir. Sumner ve Miller (1996)'e göre sırasıyla az, çok fazla, fazla sınıfında bulunmuştur. Sumner ve Miller (1996)'e göre toprakların \% 56.6'sında Mg yeterlilik sınırının (160-480 $\mathrm{mg} \mathrm{kg}^{-1}$ ) üzerinde iken \% 36.7'sinde yeterlilik sınırında (160-480 $\mathrm{mg} \mathrm{kg}^{-1}$ ) ve $\% 6.7$ 'sinde yeterlilik sınırının (160-480 $\left.\mathrm{mg} \mathrm{kg}^{-1}\right)$ altındadır. Araştırma alanı topraklarında Fe içeriği $1.97 \mathrm{mg} \mathrm{kg}^{-1}$ ile $11.28 \mathrm{mg} \mathrm{kg}^{-1}$ arasında değişkenlik göstermiştir. Lindsay ve Norwell (1978)'e göre topraklar az ve fazla sınıfına ayrılmıştır. Toprakların \% 16.7'sinde $\mathrm{Fe}$ az ve \% 50.0'sinde fazla bulunmuştur. Toprakların alınabilir $\mathrm{Cu}$ elementi miktarı 0.10 ile $7.95 \mathrm{mg} \mathrm{kg}^{-1}$ arasında oldukça farklı değişkenlik göstermiştir. Follet (1969)'e göre toprakların \% 23.3'ü Cu yeterlilik sınırının $(<0.2)$ altında iken \%76.7'si yeterlilik seviyesinde $(0.2<)$ bulunmuştur. Topraklarda Zn miktarı en düşük $0.09 \mathrm{mg} \mathrm{kg}^{-1}$, en yüksek $2.78 \mathrm{mg} \mathrm{kg}^{-1}$, ortalama $0.861 \mathrm{mg} \mathrm{kg}^{-1}$ dir.
Sillanpää (1990)'ya göre toprakların \% 60'ında $\mathrm{Zn}$ 'nin yeterlilik seviyesinin (0.7-2.4 $\left.\mathrm{mg} \mathrm{kg}^{-1}\right)$ altında olduğu tespit edilmiştir. Ülkemizdeki tarım topraklarında genellikle düşük düzeyde belirlenen $\mathrm{Zn}$, bitkilerdeki olumlu etkileri fazla olmasına rağmen üreticiler bu besin elementi ile gübrelemeye yeterince özen göstermemektedir (Yağmur ve Okur, 2015). Ayrıca Özgüven ve Katkat (2002) topraktaki OM miktarı ile yarayışlı Zn miktarı arasında doğru orantı olduğunu, organik maddenin yüksek olduğu üst katmanlarda yarayışlı $\mathrm{Zn}$ miktarının artacağını bildirmişlerdir. Çinkonun bitkilere yarayışlılığını etkileyen etmenlerin başında gelen toprak pH'sı arttıkça çinkonun yarayışlılığını azaltmaktadır (Kacar ve Katkat, 1998). Alınabilir Mn miktarı en düşük $2.82 \mathrm{mg} \mathrm{kg}^{-1}$, en yüksek $24.32 \mathrm{mg}$ $\mathrm{kg}^{-1}$ ve ortalama $9.383 \mathrm{mg} \mathrm{kg}{ }^{-1}$ dır. Sillanpää (1990)'ya göre toprakların \% 76.7'sinde $M n$ düşük bulunmuştur. Kireçli alkalin topraklarda manganın güç çözünen oksitlerinin ve hidroksitlerinin bolca bulunması, bitkilerde $\mathrm{Mn}$ alımının az olmasının temel nedenidir (McKenzie, 1989). Toprakların N miktarı en düşük \% 0.04, en yüksek $\% 0.18$ ve ortalama \% 0.096'dır. Sillanpää (1990)'ya göre toprakların \% 46.7'sinde $\mathrm{N}$ miktarı yeterlilik seviyesinin (\% 0.090-0.170) altındadır.

Yapılan literatür araştırmalarına göre Başaran ve Okant (2005) kiraz bahçesi topraklarının \% 62 'sinde N'un yeterli, \% 74' ünde P'un yeterli, \% $46^{\prime}$ sında K'un yeterli, Fe ve Mn'ın yetersiz, $\mathrm{Zn}^{\prime}$ nun yeterli olduğunu belirtmişlerdir. Zengin ve ark. (2007) Karaman'da elma bahçesinde toprak ve yaprak örneklerinde besin elementlerini incelemişler, topraktaki Fe'in yeterlilik seviyesinin (4.5 $\mathrm{mg} \mathrm{kg}^{-1}$ ) altında olduğu ve toprakların \% 53.5'inde elverişli Fe'nin yetersiz olduğunu bildirmişlerdir. Aynı araştırıcılar, toprakların $\mathrm{Cu}$ miktarını 0.6-6.3 $\mathrm{mg} \mathrm{kg}^{-1}$ arasında olup yeterlilik sınırına göre $\left(0.2 \mathrm{mg} \mathrm{kg}^{-1}\right)$ toprakların tamamında $\mathrm{Cu}$ yeterli, $\mathrm{Mn}$ içeriği yeterlilik seviyesinin $(5 \mathrm{mg} \mathrm{kg}$ $\left.{ }^{1}\right)$ altında, Zn yeterlilik sınırının (0.54 mg kg-1) altında bulmuşlardır. Yıldız ve Uygur (2016) ceviz bahçeleri topraklarının \% 69'unu P, \%78'ini Mg, $\% 96$ 'sını Zn ve \%98'ini K yönünden fakir, \%45'i Ca yönünden yüksek bulmuşlardır. Abacı Bayan (2018), Kırşehir ilinde sulu ve kuru tarım yapılan toprakların $\mathrm{pH}^{\prime}$ sını 7.27-8.19, kirecini \% 2.55-21.24, toplam tuzluluğunu \% 0.003-0.040, OM'sini \% 1.253.86, yarayışlı $\mathrm{P}_{2} \mathrm{O}_{5}$ miktarını $1.92-9.00 \mathrm{~kg} \mathrm{da}^{-1}$ ve alınabilir $\mathrm{K}_{2} \mathrm{O}$ miktarını 70.18-1614.59 $\mathrm{kg} \mathrm{da}^{-1}$ arasında değiştiğini tespit etmiştir.

Çalışmada bahçelerden alınan bitki örnekleri üzerinde yapılan analizlere ait bulgular Çizelge 2 'de verilmiştir. 
Çizelge 2. Bitki örneklerine ait bazı mineral besin elementi analiz sonuçları ve betimleyici istatistikler.

\begin{tabular}{|c|c|c|c|c|c|c|c|c|c|}
\hline Bitki & $P$ & $\mathrm{~K}$ & $\mathrm{Ca}$ & $\mathrm{Mg}$ & $\mathrm{Fe}$ & $\mathrm{Cu}$ & $\mathrm{Mn}$ & $\mathrm{Zn}$ & $\mathrm{N}$ \\
\hline & $\%$ & $\%$ & $\%$ & $\%$ & $\mathrm{mg} \mathrm{kg}^{-1}$ & $\mathrm{mg} \mathrm{kg}^{-1}$ & $\mathrm{mg} \mathrm{kg}^{-1}$ & $\mathrm{mg} \mathrm{kg}^{-1}$ & $\%$ \\
\hline Armut-1 & 0.179 & 0.773 & 3.674 & 0.327 & 130.35 & $<3$ & 88.35 & 28.68 & 1.758 \\
\hline Şeftali-1 & 0.223 & 2.011 & 2.781 & 0.506 & 71.63 & $<3$ & 94.70 & 21.80 & 3.322 \\
\hline Kiraz-1 & 0.316 & 0.067 & 0.010 & 1.013 & 98.68 & $<3$ & 54.03 & 24.72 & 2.211 \\
\hline Kiraz-2 & 0.459 & 2.616 & 0.780 & 0.427 & 68.80 & $<3$ & 108.28 & 14.72 & 2.240 \\
\hline & & & & & & $<3$ & & & \\
\hline Üzüm-1 & 0.090 & 0.269 & 1.574 & 0.311 & 76.70 & & 84.83 & 24.70 & 2.471 \\
\hline Üzüm-2 & 0.223 & 0.672 & 2.087 & 0.383 & 114.18 & $<3$ & 94.43 & 26.13 & 2.671 \\
\hline Üzüm-3 & 0.137 & 0.053 & 18.031 & 0.422 & 197.60 & $<3$ & 61.30 & 24.76 & 0.282 \\
\hline Ceviz-1 & 0.126 & 0.629 & 1.387 & 0.427 & 90.18 & $<3$ & 230.00 & 20.57 & 2.795 \\
\hline Ceviz-2 & 0.112 & 0.773 & 1.153 & 0.462 & 87.70 & $<3$ & 302.50 & 19.83 & 2.316 \\
\hline Ceviz-3 & 0.207 & 1.680 & 3.558 & 0.774 & 122.30 & $<3$ & 505.00 & 33.68 & 2.285 \\
\hline Elma-1 & 0.270 & 2.284 & 0.010 & 0.372 & 86.18 & $<3$ & 57.35 & 19.12 & 2.593 \\
\hline Elma-2 & 0.407 & 2.256 & 0.010 & 0.222 & 72.83 & $<3$ & 38.35 & 18.47 & 1.300 \\
\hline Elma-3 & 0.321 & 2.544 & 0.010 & 0.565 & 134.20 & $<3$ & 53.40 & 31.14 & 2.440 \\
\hline Elma-4 & 0.410 & 2.630 & 0.616 & 0.468 & 123.30 & $<3$ & 91.30 & 28.56 & 2.216 \\
\hline Elma-5 & 0.230 & 2.832 & 0.010 & 0.702 & 96.30 & $<3$ & 49.85 & 21.47 & 2.269 \\
\hline Minimum & 0.09 & 0.05 & 0.01 & 0.22 & 68.80 & - & 38.35 & 14.72 & 0.28 \\
\hline Maksimum & 0.46 & 2.83 & 2.781 & 1.01 & 197.60 & - & 505.00 & 33.68 & 3.32 \\
\hline Ortalama & 0.247 & 1.472 & 4.048 & 0.492 & 104.727 & - & 127.577 & 23.888 & 2.211 \\
\hline Varyans & 0.013 & 1.036 & 6.138 & 0.040 & 1105.990 & - & 15518.01 & 25.796 & 0.471 \\
\hline Std. sapma & 0.113 & 1.018 & 7.835 & 0.199 & 33.256 & - & 124.571 & 5.079 & 0.686 \\
\hline Çarpıklık & 0.447 & -0.085 & 2.410 & 1.306 & 1.414 & - & 2.190 & 0.213 & -1.436 \\
\hline Basıklık & -0.862 & -1.709 & 4.744 & 1.506 & 2.251 & - & 4.255 & -0.551 & 2.897 \\
\hline
\end{tabular}

$\mathrm{P}=$ Yarayışlı fosfor, $\mathrm{K}=$ Alınabilir potasyum, Ca=Alınabilir kalsiyum, Mg=Alınabilir magnezyum, Fe=Alınabilir demir, $\mathrm{Cu}=$ Alınabilir bakır, Mn=Alınabilir mangan, $\mathrm{Zn}=$ Alınabilir çinko, $\mathrm{N}=$ Toplam azot

Çizelge 2'ye göre armut yaprakları makro ve mikro besin elementleri Alpaslan ve ark. (2004)'na göre değerlendirilmiştir. N'un noksan (\% 1.758), yarayışlı P miktarının yeterli (\% 0.179), K miktarının noksan (\% 0.773), Ca'un fazla (\% 3.674), Mg'un yeterli (\% 0.327), alınabilir Fe'in yeterli (130.35 mg $\mathrm{kg}^{-1}$ ), Cu'ın noksan, Mn'ın yeterli (88.35 mg kg-1), Zn'nun yeterli ( $28.68 \mathrm{mg} \mathrm{kg}^{-1}$ ) olduğu belirlenmiştir.

Topraklarda $\mathrm{Mn}$ noksanlığının olmasından dolayı yapraklarda da $\mathrm{Mn}$ noksanlığının olması beklenirken bu elementin yeterli seviyede bulunması üreticilerin yapraktan element uygulama yapmasına bağlı olarak değişkenlik göstermiştir. Gürel ve Başar (2014) Bursa'da armut (Pyrus communis L.) bahçelerinde besin elementleri yönünden beslenme durumlarının belirlemek için yürüttükleri çalışmada; armut yapraklarında $\mathrm{N}$ yeterli, yaprakların yarısında $\mathrm{K}, \mathrm{Ca}$ ve $\mathrm{Mg}$ yetersiz, yaprak örneklerinin hepsinde ise $P$ konsantrasyonları bakımından bir eksiklik görülmediği bildirilmiştir. Tüfenkçi ve ark. (2002) Van'da armut bahçelerinde yaptıkları çalışmada; armut bahçelerinin yapraklarının \% 72'si N, \% 14'ü $\mathrm{P}, \% 47$ 'si $\mathrm{K}, \mathrm{Mn}$ ve $\mathrm{Zn}$ yönünden fakir, ayrıca bahçe topraklarının $\mathrm{CaCO}_{3}$ ve kil içeriği ile yaprakların $\mathrm{Mn}$ içeriği arasında önemli negatif ilişki bulunduğu belirtilmiştir.

Şeftali yapraklarındaki besin elementleri Alpaslan ve ark. (2004)'na göre değerlendirilmiştir. N'un \% 3.322 ile yeterli, P oranının yeterli (\% 0.223), K miktarının yeterli (\% 2.011), Ca'un fazla (\%2.781), Mg'un yeterli (\% 0.506), alınabilir Fe'in $71.63 \mathrm{mg} \mathrm{kg}^{-1}$ ile noksan, Cu'ın noksan, $\mathrm{Mn}^{\prime} ı \mathbf{n} 94.70$ $\mathrm{mg} \mathrm{kg}^{-1}$ ile yeterli ve $\mathrm{Zn}^{\prime}$ nun yeterli (21.80 $\mathrm{mg} \mathrm{kg}^{-1}$ ) olduğu bulunmuştur. Yapılan literatür araştırmaları sonucunda, Yağmur ve Okur (2015) tarafından Manisa'nın Salihli ilçesi şeftali bahçeleri topraklarının organik madde içeriklerinin az, kumlu tın bünyeli, topraktaki fosforun ve çinkonun az, yapraktaki çinkonun da az olarak belirlenmesi 
araştırmamızla benzerlik göstermektedir. Bayram ve ark. (2016) İzmir'de şeftali bahçelerinin beslenme durumlarını belirlemek için yaptıkları çalışmada; genel olarak topraklarda $\mathrm{P}, \mathrm{K}$ ve $\mathrm{Zn}$; bitkilerde ise $\mathrm{N}, \mathrm{K}, \mathrm{Fe}, \mathrm{Cu}, \mathrm{Zn}$ ve $\mathrm{Mn}$ miktarlarını yetersiz bulduklarını, bunun için yapraktan mikro besin elementleri içeren gübre uygulamalarının daha etkili olacağını bildirmişlerdir.

Kiraz yapraklarındaki besin elementleri Alpaslan ve ark. (2004)'na göre değerlendirilmiştir. Yarayışlı P miktarı \% $0.316-0.459$ arasında bulunmuş ve yeterli, $\mathrm{K}$ miktarı \% 0.067 ile \% 2.616 arasında değişkenlik göstermiş ve noksan, Ca miktarı \% 0.010-0.780 arasında bulunmuş ve noksan, Mg miktarı \% 0.427-1.013 arasında değişmiş ve yeterli, Fe miktarı 68.80-98.68 $\mathrm{mg} \mathrm{kg}^{-1}$ arasında değişmiş ve yeterli, Cu miktarı noksan, $\mathrm{Mn}$ miktarı 54.03 ile $108.28 \mathrm{mg} \mathrm{kg}^{-1}$ arasında değişerek yeterli, Zn miktarı 14.72-24.72 $\mathrm{mg} \mathrm{kg}^{-1}$ arasında değişerek noksan, toplam N miktarı \% 2.211-2.240 arasında değişmiş ve yeterlidir. Uysal ve Katkat (2005), Bursa'da kiraz ağaçlarının, demir, çinko, mangan ve bakır ile beslenme durumlarını belirlemek için yürüttükleri çalışmada, bahçelerin her iki dönemde de bakır ile beslenme sorunu olmadığını, yıllara göre bahçelerin \% 58-83'ünde demir, \% 21-42'sinde mangan ve \% 88-92'sinde çinkonun optimum değerlerin altına düştüğünü ortaya koymuşlardır. Başaran ve Okant (2005), Eldivan'da kirazların makro ve mikro besin elementleri bakımından beslenme durumunun belirlenmesi için yürüttükleri çalışmada, N, K, Fe, $\mathrm{Mn}$ gibi bitki besin elementlerinin toprak ve bitki örneklerinde yetersiz bulunduğunu, fakat yüksek düzeyde $\mathrm{Mg}$ ve yeterli düzeyde $\mathrm{Cu}$ ve $\mathrm{Zn}$ belirlendiğini, bitkilerin $\mathrm{Ca}, \mathrm{N}$ ve $\mathrm{Mn}$ içerikleri arasında önemli ilişkiler saptandığını bildirmişlerdir.

Üzüm yapraklarındaki besin elementleri Alpaslan ve ark. (2004)'na göre değerlendirilmiştir. Yarayışı P miktarı \% 0.090-0.223 arasında fazla değişkenlik göstermiş ve noksan, $\mathrm{K}$ miktarı \% 0.0530.672 arasında değişmiş ve noksan, Ca miktarı \% 1.574-18.031 arasında farklı değişkenlik göstermiş ve fazla, Mg miktarı \% 0.311-0.422 arasında değişmiş ve yeterli, Fe miktarı 76.70-197.60 mg kg-1 arasında değişmiş ve yeterli, Cu miktarı noksan, $\mathrm{Mn}$ miktarı 61.30-94.43 $\mathrm{mg} \mathrm{kg}^{-1}$ arasında değişmiş ve yeterli, Zn miktarı 24.70-26.13 $\mathrm{mg} \mathrm{kg}^{-1}$ arasında değişmiş ve yeterli, $\mathrm{N}$ miktarı \% 0.282-2.671 arasında değişmiş ve noksandır. Yıldız (2019), Manisa'da yürüttüğü çalışmada, bitki analiz sonuçlarında; \% 100'ünde $\mathrm{N}$ miktarının yeterli ve fazla olduğu, \% 33'ünde K, \% 53'ünde Ca miktarının noksan olduğu belirlemiştir. Analiz edilen yaprakların tamamının $\mathrm{Fe}, \mathrm{Zn}, \mathrm{Mn}$ ve $\mathrm{Cu}$ bakımından yeterli beslendiği saptamıştır. Sönmez ve ark. (2013) Siirt'te bazı yerel üzüm çeşitlerinin beslenme durumlarını belirlemek için yürüttükleri araştırmada; yaprak örneklerinde, bağlarda N, Mn ve $\mathrm{Cu}$ besin elementi dışında diğer besin elementleri açısından noksanlık olduğu belirlenmiştir.

Ceviz yapraklarındaki besin elementleri Alpaslan ve ark. (2004)'na göre değerlendirilmiştir. Yarayışı P miktarı \% 0.112-0.207 arasında değişmiş ve yeterli, $K$ içeriği \% $0.629-1.680$ arasında değişkenlik göstermiş ve noksan, Ca içeriği \% 1.153-3.558 arasında farklı değişkenlik göstermiş ve yeterli, $\mathrm{Mg}$ miktarı \% 0.427-0.774 arasında değişmiş ve yeterli, Fe miktarı 87.70-122.30 mg kg-1 arasında değişmiş ve yeterli, Cu miktarı noksan, $\mathrm{Mn}$ miktarı 230.00-505.00 $\mathrm{mg} \mathrm{kg}^{-1}$ arasında değişmiş ve fazla, Zn miktarı 19.83-33.68 $\mathrm{mg} \mathrm{kg}^{-1}$ arasında değişmiş ve yeterli, $\mathrm{N}$ miktarı \% 2.285-2.795 arasında değişmiş ve yeterlidir. Yıldız ve Uygur (2016) tarafından ceviz yapraklarının \% 29'unda $\mathrm{P}$, \% 76'sında K, \% 80'ninde $\mathrm{Mg}, \% 78$ 'inde $\mathrm{Fe}, \%$ 94'ünde $\mathrm{Zn}$ ve $\mathrm{Cu}$ değişen derecede noksanlıkları olduğunu, yaprakların \% 4'ünde $\mathrm{N}$ noksanlığı bulunduğunu saptamışlardır. Solmaz (2014) Tekirdağ'da ceviz yaprak örneklerinin \% 85'inde $\mathrm{N}$, \% 4'ünde $\mathrm{P}, \mathrm{K}, \mathrm{Mg}$, \% 2'sinde $\mathrm{Ca}$ noksanlığını, Adıman (2013)'da Tokat'ta ceviz yapraklarının \% 69'unda N, \% 57'sinde $P, \% 42$ 'sinde $K, \% 71$ 'inde $\mathrm{Mg}$ ve \% 74'ünde $\mathrm{Ca}$ eksikliği olduğunu bildirmişlerdir.

Elma yapraklarındaki besin elementleri Alpaslan ve ark. (2004)'na göre değerlendirilmiştir. Yarayışı P miktarı \% 0.230 ile \% 0.410 arasında değişmiş ve yeterli, $K$ miktarı \% 2.256-2.832 arasında bulunmuş ve fazla, Ca miktarı \% 0.0100.616 arasında değişkenlik göstermiş ve noksan, Mg miktarı \% 0.222-0.702 arasında değişmekte ve yeterli, Fe miktarı 86.18-134.20 $\mathrm{mg} \mathrm{kg}^{-1}$ arasında değişmiş ve yeterli, Cu miktarı noksan, Mn miktarı $38.35-91.30 \mathrm{mg} \mathrm{kg}^{-1}$ arasında değişmiş ve yeterli, Zn miktarı 18.47-31.14 $\mathrm{mg} \mathrm{kg}^{-1}$ arasında değişmiş ve yeterli, N miktarı \% 1.30-2.595 arasında değişmiş ve yeterlidir. Özellikle elmalarda acı benek gibi sorunların önlenmesi amacıyla Ca miktarının yeterli seviyelerde olması gerekmektedir (Childers ve ark., 1995). Ceylan ve ark. (2004) Van'da, elma bahçelerinin beslenme durumlarını belirlemek için yürüttükleri çalışmada, yaprak analiz sonuçlarına göre \% 37.8'inde N, \% 13.5'i P, \% 16.2'si K, \% 94.6'sında Mn'yi yetersiz bulmuştur. Sürmeli (2015), Iğdır'da elma bahçelerinin verimlilik durumlarını inceledikleri çalışmada; yaprak örneklerinin tamamında $N$ ve $P$ yeterlilik sınırının altında kaldığını, buna karşılık örneklenen bir bahçe dışındaki diğer bahçelerde $\mathrm{K}, \mathrm{Ca}, \mathrm{Zn}, \mathrm{Mg}, \mathrm{Fe}, \mathrm{Mn}$ ve $\mathrm{Cu}$ beslenmesi açısından bir eksiklik olmadığını belirlemiştir. 
Türk Tarım ve Doğa Bilimleri Dergisi 8(4): 940-950, 2021

Çizelge 3. Meyve bahçesi alan topraklarının ve yaprak örneklerinin bazı kimyasal özellikleri arasındaki korelasyon matrisi.

\begin{tabular}{|c|c|c|c|c|c|c|c|c|c|c|c|c|c|c|c|c|c|c|c|}
\hline & $\mathrm{pH}$ & EC & $\mathrm{CaCO}_{3}$ & Kil & Silt & Kum & $\mathrm{OM}$ & Değ. K & YP & Değ.Ca & Değ.Mg & Albr.Fe & Albr.Mn & Albr.Zn & Albr.Cu & $\mathrm{N}$ & $\mathrm{K}$ (btk) & $\mathrm{N}$ (btk) & $\mathrm{Zn}(\mathrm{btk})$ \\
\hline $\mathrm{CaCO}_{3}$ & & $0,627^{* *}$ & & & & & & & & & & & & & & & & & \\
\hline Kil & & $0,742^{* *}$ & $0,848^{* *}$ & & & & & & & & & & & & & & & & \\
\hline Silt & & $0,603^{* *}$ & $0,827^{* *}$ & $0,818^{* *}$ & & & & & & & & & & & & & & & \\
\hline Kum & & $-0,708^{* *}$ & $-0,878^{* *}$ & $-0,957^{* *}$ & $-0,949 * *$ & & & & & & & & & & & & & & \\
\hline OM & & & $0,554^{* *}$ & $0,514^{* *}$ & $0,621^{* *}$ & $-0,592^{* *}$ & & & & & & & & & & & & & \\
\hline Değ.K & & $0,383^{*}$ & $0,479 * *$ & $0,425^{*}$ & $0,474^{* *}$ & $-0,471^{* *}$ & $0,395^{*}$ & & & & & & & & & & & & \\
\hline YP & $-0,482^{* *}$ & & & & & & $0,493^{* *}$ & & & & & & & & & & & & \\
\hline Değ.Mg & & $0,383^{*}$ & $0,536^{* *}$ & $0,512^{* *}$ & $0,404^{*}$ & $-0,482^{* *}$ & $0,506^{* *}$ & & & & & & & & & & & & \\
\hline Albr.Fe & & $0,664^{* *}$ & $0,718^{* *}$ & $0,773^{* *}$ & $0,816^{* *}$ & $-0,832^{* *}$ & $0,408^{*}$ & $0,530 * *$ & & & $0,389 *$ & & & & & & & & \\
\hline Albr.Mn & & & & & & & & $0,438^{*}$ & $0,384^{*}$ & & & $0,456^{*}$ & & & & & & & \\
\hline Albr.Zn & & & & & & & $0,465 * *$ & & $0,758^{* *}$ & $-0,484^{* *}$ & & & & & & & & & \\
\hline Albr.Cu & & & & & & & & $0,438^{*}$ & $0,422^{*}$ & $-0,437^{*}$ & & & & $0,630 * *$ & & & & & \\
\hline $\mathrm{N}$ & & $0,449 *$ & $0,602^{* *}$ & $0,752^{* *}$ & $0,748^{* *}$ & $-0,786^{* *}$ & $0,783^{* *}$ & $0,521^{* *}$ & $0,602^{* *}$ & & $0,392^{*}$ & $0,593^{* *}$ & $0,501^{* *}$ & $0,411^{*}$ & & & & & \\
\hline $\mathrm{K}$ (btk) & & & $0,617^{* *}$ & $0,451^{*}$ & $0,542^{* *}$ & $-0,519^{* *}$ & $0,547^{* *}$ & $0,560^{* *}$ & & & & $0,523^{* *}$ & $0,376^{*}$ & & $0,441^{*}$ & $0,554^{* *}$ & & & \\
\hline $\mathrm{Ca}$ (btk) & & $0,514^{* *}$ & & & & & & & & & & & & & & & & & \\
\hline $\mathrm{Mg}(\mathrm{btk})$ & $0,429^{*}$ & & & & & & & & & & & & & & & & & & \\
\hline$P(b t k)$ & & & & & & & $0,388^{*}$ & & $0,410^{*}$ & $-0,511^{* *}$ & & & & $0,536^{* *}$ & $0,559 * *$ & & $0,673^{* *}$ & & \\
\hline $\mathrm{N}$ (btk) & & $0,542^{* *}$ & $0,565^{* *}$ & $0,607^{* *}$ & $0,591^{* *}$ & $-0,628^{* *}$ & & & & & & $0,561^{* *}$ & & & & $0,396^{*}$ & & & \\
\hline $\mathrm{Fe}(\mathrm{btk})$ & & & & & & & & & & & & & & & & & &,$- 641 * *$ &, $599 * *$ \\
\hline
\end{tabular}

$\left(^{*}=p<0.05\right.$ : istatistiksel olarak anlamlı fark vardır, ${ }^{* *}=p<0.01$ : Yüksek düzeyde olarak anlamlı fark vardır) pH=Toprak reaksiyonu, EC=Toplam tuzluluk, CaCO3= Toplam kireç, OM=Organik madde, YP=Yarayışıl fosfor, Değ. K= Değişebilir potasyum, Değ. $\mathrm{Ca}=$ Değişebilir kalsiyum, Değ. Mg= Değişebilir Magnezyum, Albr. Fe= Yarayışlı demir, Albr. Mn= Yarayışı mangan, Albr. Zn= Yarayışlı çinko, Albr. Cu= Yarayışlı bakır, N=Azot, Btk= Bitki 
$\mathrm{Bu}$ çalışmada meyve bahçesi yaprak örneklerinin \% 6.7'sinde $\mathrm{Mg}$, \% 20.0'sinde $\mathrm{P}$, \% 33.3'ünde $\mathrm{N}, \%$ 46.7'sinde $\mathrm{K}, \%$ 53.3'ünde Ca seviyesi noksan, \% 86.7'si Fe ve yine \% 86.7'si Mn elementi yönünden yeterlilik sınırındadır. Ayrıca yaprakların tamamında (\%100) Cu'ın ve \% 46.7'sinde Zn'nun noksan olması toprak örneklerinin çoğunda da aynı elementlerin yetersiz bulunmasının yanı sıra, yüksek pH, yüksek kireç ve $P \quad$ seviyelerinden kaynaklanabileceği düşünülmektedir. Toprak örneklerinde $\mathrm{Cu}$ yetersizliği (\% 23.3) az olduğu halde yaprakların tamamında $\mathrm{Cu}$ noksanlığının bulunması topraktaki yüksek $P$ ve N seviyeleri (Oktay ve Zengin 2005) ile antagonizmden (Aktaş ve Ateş, 1998) ileri gelebilmektedir. Çalışma alanındaki meyve bahçelerine ait toprak ve bitkilerin yaprak örnekleri fiziksel ve kimyasal içerikleri bakımından değerlendirilmiş ve istatistiksel ilişkileri (Açıkgöz ve ark., 1994)'e göre yapılmıştır (Çizelge 3).

Toprak analiz sonuçları ile yaprak analiz sonuçları arasında yapılan korelasyon analizlerine göre, toprak $\mathrm{pH}$ 'sı ile yarayışlı $\mathrm{P}\left(\mathrm{r}\right.$ : $\left.-0.482^{* *}\right)$ ve yaprağın $\mathrm{Mg}\left(\mathrm{r}: 0.429^{*}\right)$, toprağın $\mathrm{EC}^{\prime}$ si ile $\mathrm{CaCO} 3(\mathrm{r}$ : $\left.0.627^{* *}\right)$, kil (r: $\left.0.742^{* *}\right)$, silt ( $\left.r: 0.603^{* *}\right)$, kum (r: $\left.0.708^{* *}\right), \quad \mathrm{K}\left(\mathrm{r}: 0.383^{*}\right), \mathrm{Mg}\left(\mathrm{r}: 0.383^{*}\right)$, Fe ( $\mathrm{r}$ : $\left.0.664^{* *}\right), \mathrm{N}\left(\mathrm{r}: 0.449^{*}\right)$, yaprağın Ca'u (r: $\left.0.514^{* *}\right)$, yaprağın N'u (r: 0.542**) arasında farklı önem düzeylerinde $(p<0.01, p<0.05)$ önemli pozitif ve negatif ilişkiler saptanmıştır. Kireç ve organik madde arasında pozitif ( $r$ : $0.554^{* *}$ ) bir ilişki mevcutken kireç ve kum oranı arasında negatif ( $r$ : $0.878^{* *}$ ) bir ilişki görülmüştür. Topraktaki $\mathrm{Fe}$ elementi toprağın $\mathrm{K}\left(\mathrm{r}: 0.530^{* *}\right), \mathrm{Mg}\left(\mathrm{r}: 0.389^{*}\right)$, Fe elementi kil ve silt oranı ile pozitif $\left(r: 0.773^{* *}, r\right.$ : $0.816^{* *}$ ) bir ilişki vermiştir. Topraktaki $\mathrm{Mn}$ elementi Fe, $\mathrm{K}$ ve $\mathrm{P}$ ile pozitif ilişki ( $\mathrm{r}$ : $0.456^{*}$, $\mathrm{r}$ : $\left.0.438^{*}, r: 0.384^{*}\right)$ göstermiştir. Cu elementi ise toprağın $\mathrm{K}, \mathrm{P}$ ve $\mathrm{Zn}$ ile pozitif bir ilişki ( $\mathrm{r}: 0.438^{*}$, $\mathrm{r}$ : $\left.0.422 *, r: 0.630^{* *}\right)$, Ca ile negatif ilişki ( $\left.r:-0.437^{*}\right)$ vermiş, $\mathrm{Zn}$ elementi ise toprağın organik maddesi ve fosforu ile pozitif ilişki ( $r: 0.465^{* *}$, r: $0.758^{* *}$ ), Ca ile negatif ilişki ( $r$ : $-0.484^{*}$ ) vermiştir (Çizelge 3). Yaprakların $\mathrm{K}$ ve $\mathrm{N}$ içerikleri ile toprakların bazı fiziksel ve kimyasal özellikleri (toplam kireç, kum, silt, Fe, N) arasında pozitif ilişki varken kum oranı arasında negatif ilişki vardır (Çizelge 3). Yapılan çalışmalarda bitkilerin beslenme durumlarının yapraklardaki besin elementi içeriği ve yetiştiği topraktaki besin elementi içeriği arasındaki korelasyonların varlığı, meyvelerin gelişme periyodunda, yapraklarının besin elementi içeriğinin bilinmesini gerekli kılmaktadır (Aydoğdu ve ark., 2016).

\section{Sonuç ve Öneriler}

Yapılan çalışmada, meyve bahçelerinin toprak ve yaprak özellikleri incelenerek beslenme sorunları olduğu, yapılan analizlere göre bitki besleme programlarının olmadığı tespit edilmiştir. Bundan dolayı üreticilerin toprak ve bitki analizleri konusunda bilinçlendirilmesi gerekmektedir. Toprak pH'sının yüksek olması meyve ağaçlarının beslenmesinde problem oluşturmuş, kirecin fazla ve organik maddenin düşük olması topraktaki çinkonun yarayışlılığını azaltmış olabilir. Ayrıca yüksek pH'nın düşürülmesi amacıyla toz kükürt uygulaması yapılmalı ve gübrelemede asit karakterli gübreler tercih edilmelidir. Toprakların \% 60 'ında $P$ düşük bulunmuş ve fosforlu gübrelerin hareketinin zor olduğunu ve fosforlu gübrelerin etkili olabilmesi için mutlaka kök derinliğine uygulama yapılması gerekmektedir. P miktarının az olduğu topraklarda daha etkili bir gübreleme uygulamasına gereksinim duyulmaktadır. Toprakların OM ve N'unun noksan olması birçok besin elementleri alımına engel ve üretim açısından daha olumsuz koşulların oluşmasına neden olacaktır. Bitki örneklerinde N, P, K, Ca, Zn ve $\mathrm{Cu}$ noksanlığı belirlenirken ve $\mathrm{Fe}$ ve $\mathrm{Mn}$ yeterlilik sınırındadır. Armut yapraklarında; N, K, $\mathrm{Cu}$, şeftalide; $\mathrm{Cu}, \mathrm{Fe}$, kirazda; $\mathrm{Ca}, \mathrm{Cu}, \mathrm{K}, \mathrm{Zn}$, üzümde; $\mathrm{P}$, $\mathrm{K}, \mathrm{Cu}, \mathrm{N}$, cevizde; K, Cu, elmada; $\mathrm{Ca}, \mathrm{Cu}$ noksanlıkları belirlenmiştir.

Elde edilen verilere göre, bölgenin toprak yapısının iyileştirilmesi ve özellikle OM miktarının arttırılması için toprakların fiziko-kimyasal analizlerinin yanı sıra yaprak analizleri yapılmalıdır. Kompost veya yeşil gübreleme uygulamaları, iyi yanmış ahır gübresi gibi organik materyali arttırıcı uygulamaların yapılması teşvik edilerek en uygun gübreleme ve bitki besleme programı hazırlanarak bilinçli üretim yapılması sağlanmalıdır.

Teşekkür: Bu çalışma; Kırşehir Ahi Evran Üniversitesi, Bilimsel Araştırma Projeleri Koordinasyon Birimi tarafından "ZRT.A4.19.009" No'lu proje ile desteklenmiştir.

Çıkar Çatışması Beyanı: Makale yazarları aralarında herhangi bir çıkar çatışması olmadığını beyan ederler.

Araştırmacıların Katkı Oranı Beyan Özeti: Yazarlar makaleye eşit oranda katkı sağlamış olduklarını beyan ederler. 


\section{Kaynaklar}

Abacı Bayan, A.A. 2018. Problems measured and evaluated of irrigated agricultural and nonirrigated. Fresenius Environmental Bulletin, 27(5): 3133-3139.

Açıkgöz, N., Akbaş, M.E., Özcan, K. ve Moghaddam, A.F. 1994. Tarımsal araştırmaların değerlendirilmesi için PC paketi TARIST. Tarla Bitkileri Kongresi, Bildiriler Kitabı, 2529 Nisan Bornova-İzmir, s. 264-267.

Adıman, M. 2013. Tokat ili Niksar ilçesi ceviz bahçelerinin mineral beslenme durumlarının belirlenmesi. Yüksek Lisans Tezi, Gaziosmanpaşa Üniversitesi Fen Bilimleri Enstitüsü, Tokat.

Aktaş, M. ve Ateş, M. 1998. Bitkilerde Beslenme Bozuklukları Nedenleri ve Tanınmaları. ISBN:975-320-033-1, Engin Yayıncllık, Ankara.

Alpaslan, M., Güneş, A. ve İnal, A.G. 2004. Gübreleme çalışmalarında bitki analizlerinin yeri ve farklı bitkiler için bitki besin maddesi kritik düzeyleri. Türkiye 3. Ulusal Gübre Kongresi, 11-13 Ekim, Tokat, s.1215-1276.

Anonim 2020a. Kırşehir Gıda, Tarım ve Hayvancılık Müdürlüğü. Kırşehir Tarımsal YatırımRehberi.https://www.tarimorman.go v.tr/SGB/TARYAT/Belgeler/il yatırım rehberleri/kirsehir.pdf (Erişim Tarihi: 03.12.2020).

Anonim 2020b. TC. Tarım ve Orman Bakanlığı Meteoroloji Genel Müdürlüğü, https:www.mgm.gov.tr/veridegerlendirme/i I ve ilçeleri istatistik Kirsehir (Erişim tarihi: 03.12.2020).

Aydoğdu E., Turan, H.S., Pekcan, T. ve Torun, B. 2016. Uslu zeytin çeşidi yapraklarındaki makro besin elementlerinin mevsimsel değişimi. Çukurova Tarım Gıda Bilimleri Dergisi 31(3): 207-213, (Özel Sayı).

Başaran, M. ve Okant, M. 2005. Bazı toprak özelliklerinin Eldivan yöresinde yetiştirilen kirazların beslenme durumu üzerine etkisi. Tarım Bilim Dergisi, 11(2): 115-119.

Bayraklı, F. 1987. Toprak ve bitki analizleri, Ondokuz Mayıs üniversitesi Yayınları, No:17, Samsun.

Bayram, S.E., Elmacı, Ö.L. ve Özden, N. 2016. İzmir ili güney hattı şeftali (Prunus persica L.) bahçelerinin beslenme durumlarının incelenmesi. Tekirdağ Ziraat Fakültesi Dergisi 13(4):27-35.
Boşgelmez, A., Boşgelmez, i. İ., Savaşçı, S. ve Paslı, N. 2001. Ekoloji-Il (Toprak), Başkent Klişe Matbaacılık, Kızılay-Ankara.

Boyacı, S., Başak, H. ve Altun, B. 2017. Potential of Kırşehir in terms of horticulture. International Journal of Science and Research, 6(10):1546-1550.

Bremner, J.M. ve Mulvaney, C.S. 1982. NitrogenTotal. In: A.L. Page, R.H. Miller (Eds). Methods of Soil Analysis. Part 2. 2nd ed. Agron. Monogr. 9. ASA and SSSA, Madison, WI, s. 595-624.

Ceylan, Ş., Karaçal, ì., Tüfenkçi, Ş. ve Gürbüz, Ö. 2004. Van yöresi elma bahçelerinin beslenme durumu. Journal of Aegean Agricultural Research Institute, 14(1):151164.

Childers, F, N., Morris, J.R. ve Sibbert, G.S. 1995. Modern Fruit Science. Horticultural publications 3906 NW 31 Place. Gainesville Florida.

Follet, R.H. 1969. Zn, Fe, Mn and Cu in Colorado Soils. Ph. D. Dissertation. Colorado State University.

Gee, G.W. ve Bauder, J.W. 1986. Particle-Size Analysis. Methods of Soil Analysis. Part1. Physical and Mineralogical Methods. 2nd Edition. Agronomy No: 9. 383-411:1188 p, Madison, Wisconsin USA.

Gürel, S. ve Başar, H. 2014. Bursa yöresinde yetiştirilen armut ağaçlarının azot, fosfor, potasyum, kalsiyum ve magnezyum ile beslenme durumlarının incelenmesi. Uludağ Üniversitesi Ziraat Fakültesi Dergisi, 28(1):111.

Heckman, J.R. 2004. Soil pH Measurement with a Portable Meter. Fact Sheet FS 767. Rutger Cooperative Res. and Ext. Serv. NJAES. New Jersey.

Helmke, P.A. ve Sparks, D.L. 1996. Lithium, Sodium, Potassium, Rubidium, and Calcium. In: Sparks D.L. Methods of Soil Analysis: Part 3 Chemical Methods, 551-574. ISBN: $9780891188254 \quad$ (Print) ISBN:9780891188667(Online), doi:10.2136/sssabookser5.3.

Herrera, E.A. 2001. Fertilization programs for apple orchards. Guide H-319. Extension Horticulturist College of Agriculture and Home Economics, New Mexico State University, 1-4.

Jones, Jr.J.B. ve Case, V.W. 1990. Sampling, Handling, and Analyzing Plant Tissue Samples, Chapter 15. In R.L. Westerman 
(ed) Soil Testing and Plant Analysis, Third Edition, SSSA, Madison, Wisconsin, USA, s. 390-420.

Kacar, B. 2009. Toprak Analizleri. Nobel Yayın No:1387, Fen Bilimleri: 90, Nobel Bilim ve Araştırma merkezi yayın No: 44.

Kacar, B. ve Katkat, A.V. 1998. Bitki Besleme. Uludağ Üniversitesi Güçlendirme Vakfı, Yayın No:127, Vipaş Yayınları: 3, 459s

Kuo, S. 1996. Phosphorus. In: Sparks D.L. Methods of Soil Analysis: Part 3 Chemical Methods, 869-921. ISBN:9780891188254 (Print) ISBN:9780891188667 (Online), doi:10.2136/sssabookser5.3.

Lindsay, W.L. ve Norvel, W.A. 1978. Development of DTPA Soil Test for $\mathrm{Zn}, \mathrm{Fe}, \mathrm{Mn}$ and $\mathrm{Cu}$. Soil Science American Journal, 42(3), 421-28.

Maas, E.V. 1986. Salt Tolerance of Plants. Applied Agricultural Research, 1:12-26.

Mckeinze, R.M. 1989. Manganese Oxide and Hydroxides p. 439-466. In:Minerals in Soil Environments. (J.B. Dixon and S.B. Weed, eds.). 2nd ed. SSSA Madison, WI.

Nelson, D.W. ve Sommers, L.E. 1996. Total Carbon, Organic Carbon, and Organic Matter. In: Sparks D.L. Methods of Soil Analysis: Part 3 Chemical Methods, 961-1011 ISBN:9780891188254 (Print) ISBN:9780891188667 (Online), doi:10.2136/sssabookser5.3.

Nelson, R.E. 1982. Carbonate and Gypsum. Methods of Soil Analysis Part 2. Chemical and Microbiological Properties Second Edition. Agronomy. No:9 Part 2. Edition P: 191-197.

Oktay, H. ve Zengin, M. 2005. Karaman yöresi elma bahçelerinin makro besin elementleri yönünden beslenme durumları. Selçuk Üniversitesi, Ziraat Fakültesi Dergisi, 19 (37): 68-78.

Özgüven, N. ve Katkat, A.V. 2002. Bursa ili topraklarının bitkiye yarayışlı çinko yönünden genel durumu. Uludağ Üniversitesi Ziraat Fakültesi Dergisi, 16:235244.

Pınar, H., Arslan, R., Bircan, M. ve Ata, A. 2008. Mersin ilindeki elma, kayısı, erik, kiraz ve şeftali bahçelerinin bazı toprak özellikleri bakımından verimlilik durumları. 4. Ulusal Bitki Besleme ve Gübre Kongresi, 8-10 Ekim Konya, 542-547.

Richards, L.A. 1954. Diagnosis and improvement of saline and alkali soils. United States Department of Agriculture Handbook, 60.
Sillanpää, M. 1990. Micronutrient assessment at country level: An international study. In: FAO Soils Bulletin. N.63. Rome.

Solmaz, Y. 2014. Tekirdağ ilinde ceviz bahçeleri beslenme durumlarının yaprak analizleriyle belirlenmesi. Yüksek Lisans Tezi, Namık Kemal Üniversitesi Fen Bilimleri Enstitüsü, Tekirdağ.

Sönmez, F., Uyak, C. ve Tüfenkçi, Ş. 2013. Siirt ve ilçelerinde yetiştirilen yerel üzüm çeşitlerinin beslenme sorunlarının yaprak ve toprak analizleri ile belirlenmesi. Iğdır Üniversitesi Fen Bilimleri Enstitüsü Dergisi, 3(3): 73-78.

Sumner, M.E. ve Miller, W.P. 1996. Cation Exchange Capacity and Exchange Coefficients. In D.L. Sparks (ed.) Methods of Soil Analysis, Part 3. Chemical Methods. Soil Science Society of America, Book series no. 5.

Sürmeli, S. 2015. Iğdır ilinde elma bahçelerinin toprak verimliliği ve bitki besleme durumları. Yüksek Lisans Tezi, Iğdır Üniversitesi Fen Bilimleri Enstitüsü, Iğdır, 71 sayfa.

Tüfenkçi, Ş., Ceylan, Ş. ve Karaçal, ì. 2002. Van yöresinde yetiştirilen "Mellaki" armut çeşidinin beslenme durumunun saptanması. Bahçe, 31(1-2): 1-7.

Uçgun, K., Akgül, H., Gezgin, S. ve Atasay, A. 2013. Meyve ağaçlarında beslenme durumlarının erken dönemde tespit edilmesi. Süleyman Demirel Üniversitesi Ziraat Fakültesi Dergisi 1(1): 93-98.

Uysal, E. ve Katkat, A.V. 2005. Bursa ve çevresinde yetiştirilen kiraz ağaçlarının demir, çinko, mangan ve bakır ile beslenme durumları. Uludağ Üniversitesi Ziraat Fakültesi Dergisi, 19(2):47-59.

Ülgen, N. ve Yurtsever, N. 1974. Türkiye Gübreler ve Gübreleme Rehberi. Toprak ve Gübre Araştırma Enstitüsü Müdürlüğü, Teknik Yayınlar No:28. Ankara.

Yağmur, B. ve Okur, B. 2015. Salihli (Manisa) yöresindeki şeftali (Prunus persica L.) bahçelerinin beslenme ve kirlilik durumları. Meyve Bilimi Dergisi, 2 (1):16-26.

Yıldız, E. ve Uygur, V. 2016. Uşak ili ceviz bahçelerinin mineral beslenme durumları. Süleyman Demirel Üniversitesi Ziraat Fakültesi Dergisi, 11 (2):70-78.

Yıldız, O.U. 2019. Manisa-Alaşehir yöresindeki bağların toprak ve bitki analizleri ile beslenme durumunun incelenmesi. Yüksek 
Lisans Tezi, Manisa Celal Bayar Üniversitesi Fen Bilimleri Enstitüsü. Manisa.

Zengin, M., Gökmen, F. ve Gezgin, S. 2007. Karaman yöresi elma bahçelerinin mikro besin elementleri bakımından beslenme durumları. Selçuk Üniversitesi Ziraat Fakültesi Dergisi, 21(42):96-109.
Zhang, S.L., Meng, M.E., Wang, D.S., Yang, X.L., Sun, Z. ve Wang, Z.X. 1995. A study of nutritional diagnosis of short branched apples in Henan. Henan Nongye Kexue, (1): 25-26 